\title{
Inhibition of hypoxia/reoxygenation-induced oxidative stress in HGF-stimulated antiapoptotic signaling: role of PI3-K and Akt kinase upon rac1
}

\author{
M Ozaki ${ }^{*}, 1$, S Haga ${ }^{1}$, HQ Zhang ${ }^{1}, \mathrm{~K}$ Irani $^{2}$ and S Suzuki ${ }^{1}$ \\ 1 Bioengineering Laboratory, Department of Innovative Surgery, National \\ Research Institute for Child Health and Development, Tokyo, Japan \\ 2 Division of Cardiology, Department of Medicine, Johns Hopkins University \\ School of Medicine, Baltimore, MD, USA \\ * Corresponding author: M Ozaki, Bioengineering Laboratory, Department of \\ Innovative Surgery, National Research Institute for Child Health and \\ Development, 3-35-31, Taishi-Do, Setagaya, Tokyo 154-8567, Japan. Tel: \\ +81 3 3416 0181_Ext. 8774; Fax: +81 33411 7309; \\ E-mail: mozaki@nch.go.jp
}

Received 18.3.02; accepted 19.8.02

Edited by Nunez

\begin{abstract}
Rac1-regulated reactive oxygen species (ROS) production has been implicated in apoptosis. In contrast, pleiotropic protein kinase Akt protects against apoptosis. However, the pro- and antiapoptotic mechanisms of rac1 and Akt, respectively, and the intersection between these mechanisms are incompletely understood. In a model of oxidative stress and apoptosis induced by hypoxia/reoxygenation $(\mathrm{H} / \mathrm{R})$ in primary hepatocytes, activation of the PI3-K Akt axis by the prosurvival hepatocyte growth factor (HGF) inhibited H/Rstimulated rac1 activation and intracellular ROS production, and suppressed apoptosis. Suppression of PI3-K or Akt activity abrogated the inhibitory effect of HGF on rac1 activity and rac1-regulated oxidative stress. Furthermore, constitutive activation of Akt or PI3-K in the absence of HGF was sufficient to phosphorylate rac1, inhibit rac1 activation, and suppress rac1-regulated ROS production. These findings demonstrate that growth factor-stimulated activation of PI3K-Akt is necessary and sufficient to suppress intracellular oxidative stress and apoptosis by inhibiting activation of proapoptotic, prooxidative rac1 GTPase.

Cell Death and Differentiation (2003) 10, 508-515. doi:10.1038/ sj.cdd. 4401172
\end{abstract}

Keywords: rac1; ROS; PI3-K; Akt; HGF; hypoxia; reoxygenation; apoptosis

Abbreviations: ROS, reactive oxygen species; $H / R$, hypoxia/ reoxygenation; $\mathrm{l} / \mathrm{R}$, ischemia/reperfusion; HGF, hepatocyte growth factor; 8-OHdG, 8-hydoxy-2-deoxyguanosine; NAC, Nacetyl cysteine; $\mathrm{CM}_{2} \mathrm{H}_{2} \mathrm{DCF}-\mathrm{DA}$, 5,6-chloromethyl-2,7-dichlorodihydrofluorescein diacetate

\section{Introduction}

Reactive oxygen species (ROS) such as superoxide anion and hydrogen peroxide are generated in many physiological and pathophysiological conditions. ${ }^{1-5}$ There are accumulating data indicating that regulation of the intracellular redox state is a versatile control mechanism in signal transduction in both pathological and physiological conditions. ${ }^{6}$

Ischemia/reperfusion (I/R) and hypoxia/reoxygenation $(\mathrm{H} /$ $\mathrm{R}$ ) result in the production of ROS within tissue or cells. ${ }^{2,7,8}$ The rac1 small GTPase is an important regulator of ROS production within cells under these circumstances. ${ }^{7}$ Rac1 belongs to the rho family of small GTP binding proteins and its role in the production of ROS in phagocytic cells such as neutrophils is well established. ${ }^{9-11}$ In such cells, rac proteins are essential for the assembly of the plasma membrane NADPH oxidase, which is responsible for the transfer of electrons to molecular oxygen leading to the production of superoxide anions. Rac proteins, in particular rac1, function similarly in nonphagocytic cells, ${ }^{1,12}$ and such rac1-regulated ROS have been implicated in a variety of cellular processes including growth, migration, and transformation. ${ }^{2,8,12-17} \mathrm{We}$ have recently shown that rac1-regulated ROS production also mediates apoptosis in response to $\mathrm{I} / \mathrm{R}{ }^{7}$

Hepatocyte growth factor (HGF), which was initially isolated as a potent mitogen for hepatocytes, is now known to be a broad-spectrum mitogen for a variety of cell types. ${ }^{18-22}$ In addition to these activities, HGF has morphogenic and angiogenic activities, ${ }^{23-25}$ and is involved in organ regeneration and tumorigenesis. ${ }^{26,27} \mathrm{HGF}$, after binding to its specific receptor tyrosine kinase (cMet), induces various biological effects mainly through activation of PI3-K and Akt kinases. ${ }^{28-32}$ In this respect, HGF is a prototypical prosurvival growth factor. In support of this, HGF is also known to prevent nontransformed hepatocytes from oxidant-mediated apoptosis. ${ }^{33,34}$

Although the prosurvival effects of the PI3-K-Akt pathway are well known, the roles of PI3-K or Akt in regulating intracellular oxidative stress, if any, are only beginning to be appreciated. In this report, we describe a hitherto unknown role of Akt in suppressing ROS production, and show that Aktinduced phosphorylation with subsequent inhibition of rac1 activity is responsible for this phenomenon.

\section{Results}

\section{HGF protects hepatocytes from H/R-induced apoptosis through PI3-K and Akt}

We first validated the antiapoptotic role of HGF in our model of H/R-induced apoptotic cell death. Cellular apoptosis increased following $H / R$ (Figure 1a). HGF effectively suppressed H/R-induced apoptosis. The maximum 
a apoptosis

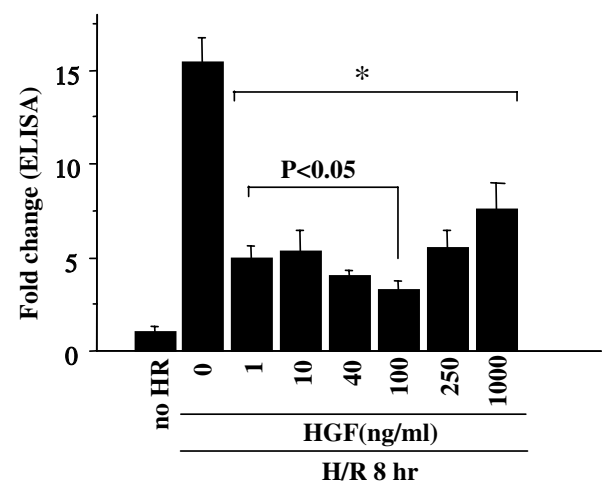

b

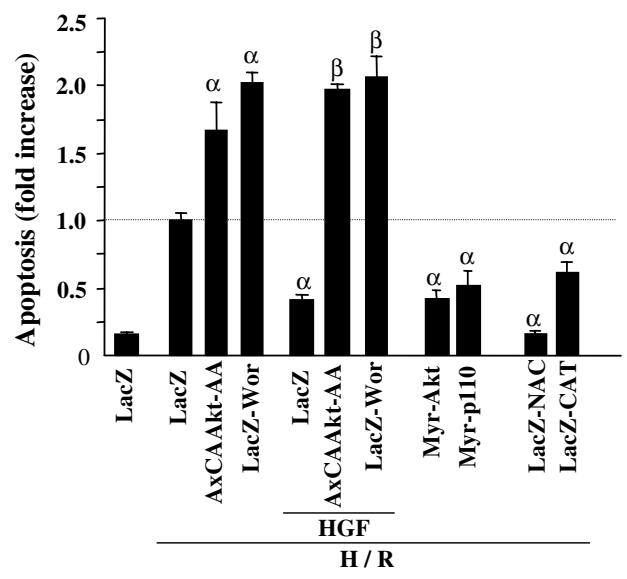

(ii)

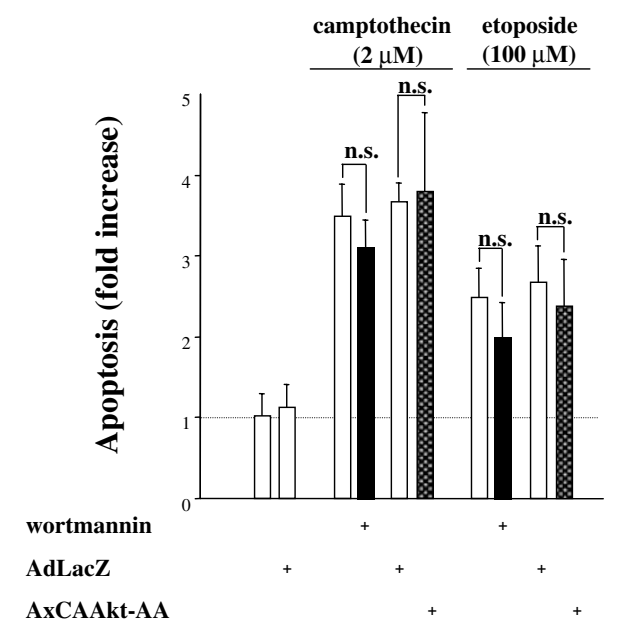

AxCAAkt-AA
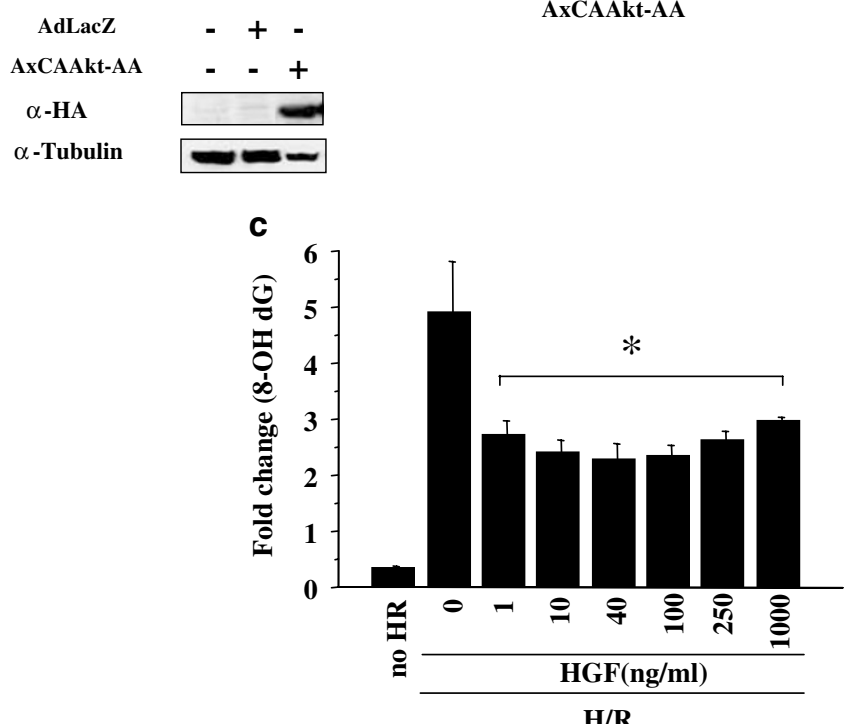

Figure 1 HGF prevents hepatocytes from apoptotic cell death through PI3-K and Akt. (a) Effects of HGF upon hepatocellular apoptosis induced by $4 \mathrm{~h} \mathrm{hypoxia} \mathrm{and} 8 \mathrm{~h}$ reoxygenation. ${ }^{*} P<0.05$ versus $\mathrm{HGF}(-)-\mathrm{H} / \mathrm{R}(+)$ group. (b) Effects of $\mathrm{PI} 3-\mathrm{K}$ and Akt upon suppressive effects of $\mathrm{HGF}$ against $\mathrm{H} / \mathrm{R}$-induced apoptosis. Culture media collected to evaluate apoptosis $8 \mathrm{~h}$ after hypoxia were applied for the assays. rhHGF, wortmannin (Wor), $N$-acetyl cysteine (NAC), or catalase (CAT) were administered $2 \mathrm{~h}$ prior to hypoxia at concentrations of $40 \mathrm{ng} / \mathrm{ml}, 0.2 \mu \mathrm{M}, 1 \mathrm{mM}$, and $1000 \mathrm{U} / \mathrm{ml}$, respectively. $\alpha: P<0.05$ versus AdLacZ-HGF $(-)-\mathrm{H} / \mathrm{R}(+)$ group, $\beta$ : $P<0.05$ versus AdLacZ-HGF(+)-H/R(+) group, Expression of dominantly negative mutant of Akt protein was confirmed by Western blotting. To show the specific inhibitory effects of wortmannin and dominant negative mutant of Akt upon PI3-K and Akt, respectively, apoptosis was measured $8 \mathrm{~h}$ after the administration of the PI3-K/Akt-independent apoptosis inducers, camptothecin or etoposide ( 2 and $100 \mu \mathrm{M}$, respectively). (c) Effects of HGF upon the generation of 8-OHdG (oxidative addicts of dsDNA) induced by $4 \mathrm{~h}$ hypoxia and $8 \mathrm{~h}$ reoxygenation. ${ }^{*} P<0.05$ versus $\mathrm{HGF}(-)-\mathrm{H} / \mathrm{R}(+)$ group. Each experiment was performed at least three times independently. All data are expressed as mean \pm S.E.M 
effects of HGF were obtained around $40-100 \mathrm{ng} / \mathrm{ml}$ in all groups.

We next determined whether the antiapoptotic effect of HGF was mediated by Akt kinase and PI3-K. HGF-stimulated protection from apoptosis was completely inhibited by adenoviral expression of a dominant-negative mutant of Akt kinase (AxCAAkt-AA) as well as a specific PI3-K inhibitor, wortmannin. Furthermore, overexpressed constitutively activated mutants of Akt or PI3-K (Myr-Akt or Myr-p110, respectively) protected $\mathrm{H} / \mathrm{R}$-induced apoptosis (Figure 1b-i). The specific inhibition of PI3-K/Akt pathway by AxCAAkt-AA or wortmannin was confirmed by $\mathrm{PI} 3-\mathrm{K} / \mathrm{Akt}$-independent apoptosis inducers, camptothecin and etoposide. Camptothecin and etoposide, proapoptotic factors independent of PI3-K/ Akt pathway, which inhibit topoisomerase I and II respectively, induced apoptosis of primary hepatocytes. Pretreatment of wortmannin and AxCAAkt-AA, however, did not have any effects upon camptothecin- and etoposide-induced apoptosis (Figure 1b-ii).

These findings show that Akt and PI3-K function as mediators of HGF-stimulated protection against $\mathrm{H} / \mathrm{R}$-induced apoptotic cell death via suppression of intracellular oxidative stress, because the antioxidants $\mathrm{N}$-acetyl cysteine (NAC) and catalase also significantly reduced $\mathrm{H} / \mathrm{R}$-induced apoptosis.

\section{HGF inhibits H/R-induced oxidative stress and apoptosis}

Intracellular redox changes closely accompany $\mathrm{H} / \mathrm{R}$-induced cell death. We therefore also examined the role of HGF in modulating $\mathrm{H} / \mathrm{R}$-stimulated oxidative stress in hepatocytes. HGF reduced $\mathrm{H} / \mathrm{R}$-induced intracellular ROS accumulation (Figure $4 \mathrm{~d}, \mathrm{f}$ ), as well as generation of 8-hydoxy-2-deoxyguanosine (8-OHdG), a marker of oxidative stress (Figure 1c). This suggests that HGF exerts its protective effect upon $\mathrm{H} / \mathrm{R}$-induced apoptosis via suppression of intracellular oxidative stress.

\section{Preactivation of Akt is required for HGF-induced cytoprotection}

With an eye toward examining the mediating role of Akt in HGF-stimulated suppression of oxidative stress, we next determined whether HGF results in Akt activation. Akt was activated by HGF 30 min after administration, and this effect was inhibited by pretreatment with PI3-K inhibitors, Ly294002 or wortmannin. Sufficient inhibitory effect of Akt kinase activity was obtained by Ly294002 at 10 and $50 \mu \mathrm{M}$, and by wortmannin at $200 \mathrm{nM}$ (Figure 2a). This suggests that stimulation with HGF results in activation of Akt through PI3$\mathrm{K}$, and that this activation may be required to protect against apoptosis. In support of this, HGF, when administered immediately following hypoxia, did not significantly suppress apoptosis induced by $\mathrm{H} / \mathrm{R}$ (Figure $2 \mathrm{~b}$ ).

\section{HGF suppresses rac1-regulated, H/R-induced ROS production through activation of Akt (Figures 3 and 4)}

We then examined the role of HGF in modulating ROS production, particularly that regulated by rac1. Adenoviral a

$\begin{array}{lcccccccc}\text { HGF }(40 \mathrm{ng} / \mathrm{ml}) & - & + & + & + & + & + & + & + \\ \operatorname{Ly} 294002(\mu M) & - & - & - & 10 & 50 & - & - & - \\ \text { Wortmannin }(\mathrm{nM}) & - & - & - & - & - & 50 & 100 & 200\end{array}$
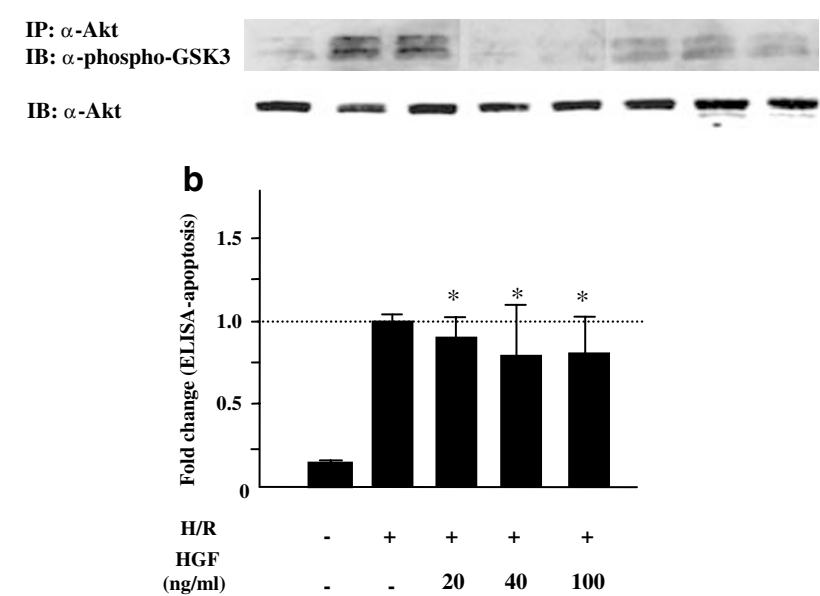

Figure 2 Preactivation of Akt is required for HGF-induced cytoprotection. (a) Activation of Akt by HGF. Akt activity was measured with or without addition of HGF. Whole-cell extracts were prepared from $3 \times 10^{6}$ cells, and immunoprecipitated with anti-Akt. After GSK-3, a substrate of Akt, was added to the reaction mixture, phosphorylation of GSK-3 was measured with anitphospho-GSK-3. (b) HGF's effects upon posthypoxic apoptotic cell death, when administered following hypoxia. rhHGF was administered just following hypoxia at the concentrations indicated, and apoptotic cell death was measured $8 \mathrm{~h}$ following hypoxia. *n.s. versus $\mathrm{HGF}(-)-\mathrm{H} / \mathrm{R}(+)$ group

expression of an activated allele of rac1 (rac1V12) resulted in an increase in intracellular ROS levels. Treatment with HGF suppressed this rise in rac1-regulated ROS in hepatocytes (Figure 3b, c). Treatment with HGF alone did not induce ROS production, nor did it result in an increased capacity to eliminate ROS directly, as determined by measuring intracellular ROS after addition of exogenous peroxide (Figure 4b, c).

We next examined whether Akt mediates HGF-stimulated suppression of intracellular ROS production. As shown in Figure 4, pretreatment with HGF inhibited $\mathrm{H} / \mathrm{R}$-induced ROS production. More importantly, this effect of HGF was abolished by adenoviral expression of dominant-negative mutants of PI3-K (AxCAdelta-p85) or of Akt (AxCAAkt-AA). As expected, $\mathrm{H} / \mathrm{R}$-induced oxidative stress was also suppressed by dominant-negative rac1 (racN17) and NAC. This suggests that Akt and PI3-K are essential mediators through which HGF inhibits oxidative stress.

We also examined whether activated Akt or PI3-K could directly affect the intracellular redox state and, specifically, rac1-regulated ROS production, independent of HGF. As demonstrated previously, expression of the activated allele of rac1 (rac1V12) resulted in an increase in oxidative stress. However, coexpression of rac1V12 with constitutively activated forms of PI3-K (Myr-p110) or Akt (Myr-Akt) inhibited this rise in intracellular ROS (Figure 3d, e). This shows that active Akt or PI3-K is sufficient to suppress intracellular oxidative stress, and acts by inhibiting rac1-regulated ROS production. 
a

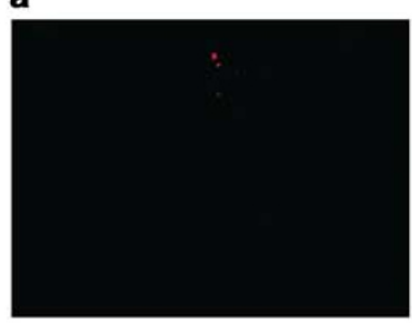

b

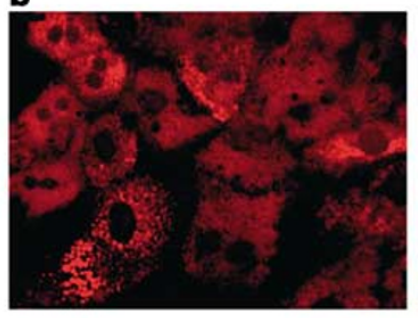

c

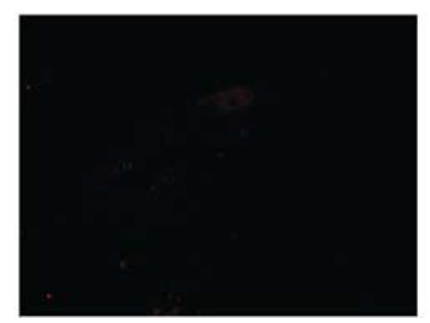

d

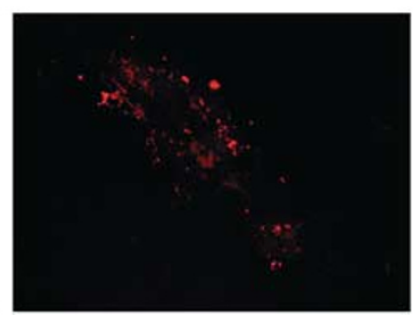

e

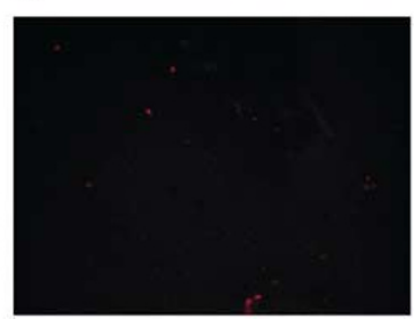

Figure 3 rac1-mediated ROS production was diminished by HGF, and by overexpressed constitutively activated PI3-K and Akt. ROS production of the hepatocytes was observed with confocal laser scan microscopy after staining cells with $\mathrm{CM}-\mathrm{H}_{2} \mathrm{DCF}-\mathrm{DA}(250 \mu \mathrm{M})$ for $10 \mathrm{~min}$. Adenovirus encoding constitutively activated mutant of rac1 (Adrac1V12) was infected $48 \mathrm{~h}$ prior to the experiment (b-f). (a) Hepatocytes infected with AdLacZ. (b) ROS production by constitutively activated rac1 (racV12). (c) 20 min after HGF addition. (d) Coinfected with constitutively activated mutant of PI3-K (Myr-p110). (e) Coinfected with constitutively activated mutant of Akt (Myr-Akt). Each photograph taken in this figure includes at least several cells and expresses a representative of at least three independent experiments. Original magnification, $\times 200$

a

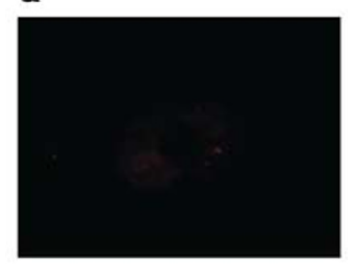

f

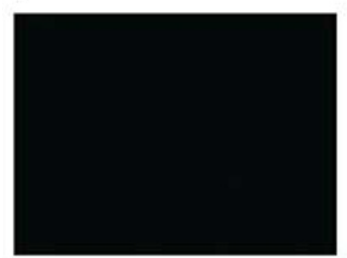

b

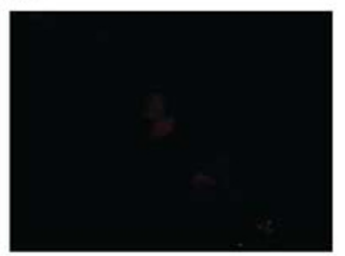

g

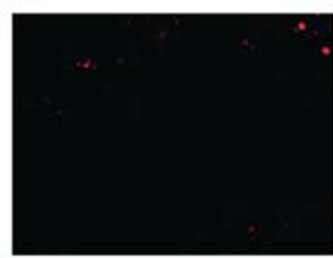

c

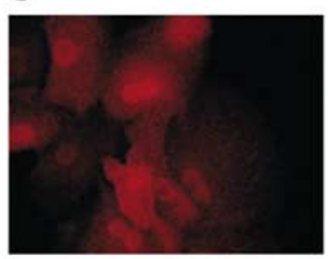

h

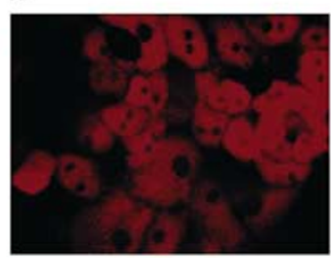

d

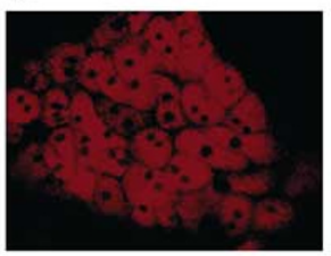

i

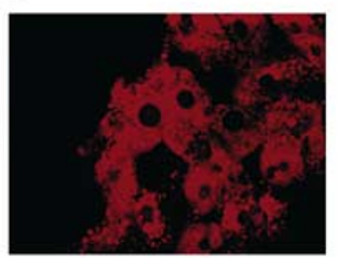

e

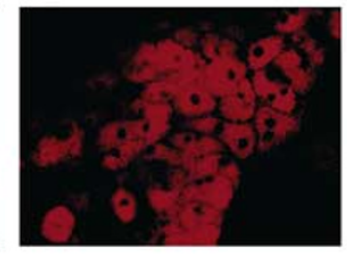

j

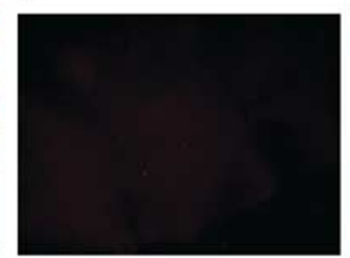

Figure 4 Measurement of cellular ROS using confocal laser scan microscopy. Hepatocytes are reoxygenated and stained with $10 \mu \mathrm{M}$ of CM- $\mathrm{H}_{2} \mathrm{DCFDA} 10$ min before observation. Adenoviruses (AxCAdelta-p85 or AxCAAkt-AA, dominantly negative mutant of PI3-K or Akt, respectively) were infected $48 \mathrm{~h}$ prior to experiment. HGF was added to the culture medium $2 \mathrm{~h}$ prior to hypoxia. (a) Normoxia. (b) $10 \mathrm{~min}$ after $\mathrm{HGF}$ addition ( $40 \mathrm{ng} / \mathrm{ml})$. (c) $10 \mathrm{~min}$ after addition of $\mathrm{HGF}$ and $\mathrm{H}_{2} \mathrm{O}_{2}(100 \mu \mathrm{M})$. (d) $\mathrm{H} / \mathrm{R}$ only (10 min reoxygenation following $4 \mathrm{~h}$ hypoxia). (e) H/R preinfected with AdLacZ. (f) H/R pretreated with HGF. (g) H/R preinfected with AdracN17 (dominant negative mutant of rac1). (h, i) H/R pretreated with HGF, and preinfected with AxCAdelta-p85 or AxCAAkt-AA, respectively. (j) H/R pretreated with NAC (10 mM). Each photograph expresses a representative of at least three independent experiments. Original magnification, $\times 200$

\section{HGF phosphorylates and inactivates rac1}

To further elucidate the molecular mechanisms responsible for the above-mentioned phenomena, we examined the effect of HGF and Akt on (1) rac1 activity, and (2) post-translational modification of rac1. Rac1 was activated within minutes after $\mathrm{H} / \mathrm{R}$ (Figure $5 \mathrm{a}$ ). Pretreatment with $\mathrm{HGF}$ reduced $\mathrm{H} / \mathrm{R}$-induced rac1 activation (Figure $5 \mathrm{~b}$ ). This inhibitory effect of HGF on posthypoxic rac 1 activity was abolished by suppressing PI3-K or Akt activation. Consistent with these findings, expression of constitutively active PI3-K or Akt (Myr-p110 or Myr-Akt, respectively) also suppressed posthypoxic rac1 activation (Figure 5c). These observations indicate that HGF inhibits activation of rac1 through the PI3-K-Akt pathway.

A recent report shows that rac1 has a putative Akt phosphorylation site, and that serine phosphorylation of rac1 by Akt results in inhibition of GDP-GTP exchange in vitro. ${ }^{35}$ If true in vivo, this could provide the molecular basis for the inhibitory effect of HGF, via Akt and PI3-K, on rac1 activity. We therefore examined whether HGF modulates serine phos- 
a

Hypoxia 4h /
Reoxygenation
IP:PAK-1 PBD
IB: $\alpha-R a c 1$
IB: $\alpha-$ Rac1
H/R 10min
HGF(40ng/ml)
AdLacZ
AxCAdelta-p85
AxCAAkt-AA
Wortmannin $(0.2 \mu M)$
Ly294002 (50 $\mu$ M)
IP:PAK-1 PBD
IB: $\alpha-$ Rac1
IB: $\alpha-$ Rac1
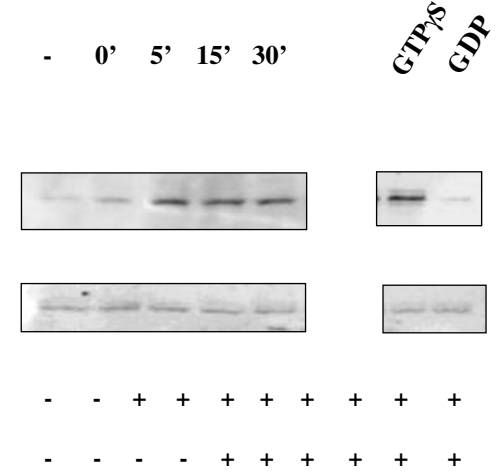

$-++-++$

- $\quad-\quad-\quad-\quad+\quad-\quad-$

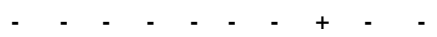

- $\quad-\quad-\quad-\quad-\quad-\quad+\quad-$

- $\quad-\quad-\quad-\quad-\quad-\quad-\quad-\quad-\quad+$
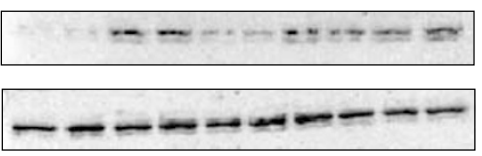

C

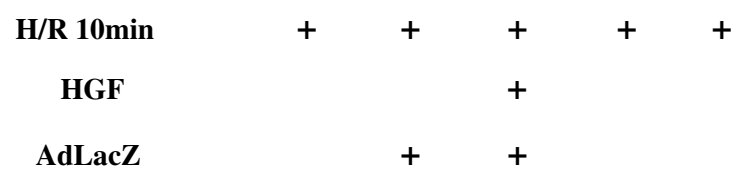

Myr-p110

Myr-Akt

$+$

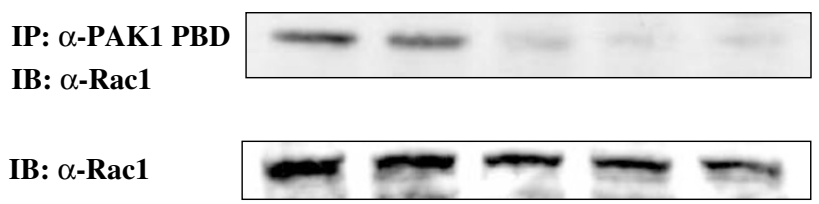

Figure 5 HGF inactivates rac1 through $\mathrm{Pl} 3-\mathrm{K}$ and Akt. (a-c) rac1 activity assay. (a), rac1 is activated following hypoxia and $H / R$. Whole-cell extracts were immunoprecipitated with p21-binding domain of PAK-1 (PAK-1 PBD) and blotted with anti-rac1. (b) Suppression of H/R-induced rac1 activity by HGF through PI3$\mathrm{K}$ and Akt. (c) Suppression of $\mathrm{H} / \mathrm{R}$-induced rac1 activation was abolished completely by HGF, Myr-p110, and Myr-Akt

phorylation of rac1. Rac1 was constitutively serine phosphorylated under basal conditions, and $H / R$ resulted in dephosphorylation of rac1. Treatment with HGF phosphorylated rac1 even under normoxic conditions, and inhibited H/Rstimulated serine dephosphorylation of rac1 (Figure 6a). This suggests that HGF inhibits activation of rac1 by maintaining it in the phosphorylated form (and thus suppressing GDP-GTP exchange), an effect that may be mediated via Akt. Furthermore, overexpression of constitutively activated mutants of PI3-K or Akt also inhibited H/R-stimulated serine dephosphorylation of rac1 (Figure 6b). These data suggest a

$\begin{array}{ccccccc}\text { H/R } 10 \text { min } & - & - & + & + & + & + \\ \text { HGF } & - & + & - & - & + & +\end{array}$

IP: $\alpha-\operatorname{Rac1}$

IB: $\alpha$-Phospho serine

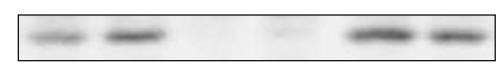

IB: $\alpha-\operatorname{Rac1}$

b

\begin{tabular}{|c|c|c|c|c|c|}
\hline H/R 10min & - & - & + & + & + \\
\hline AdLacZ & & + & + & & \\
\hline Myr-p110 & & & & + & \\
\hline Myr-Akt & & & & & + \\
\hline $\begin{array}{l}\text { IP: } \alpha \text {-Rac1 } \\
\text { IB: } \alpha-P h o s p h o \text { serine }\end{array}$ & - & $m$ & $-a$ & $\dot{H}$ & - \\
\hline IB: $\alpha-\operatorname{Rac} 1$ & & - & & & - \\
\hline
\end{tabular}

Figure 6 rac1 phosphorylation assay. Treatment with HGF (a) and constitutively activated mutants of PI3-K or Akt (b) phosphorylate rac1 in normoxic conditions and prevent serine dephosphorylation of rac1 after $H / R$. Whole-cell extracts were immunoprecipitated with anti-rac1 and blotted with antiphosphoserine. Each assay expresses the representative of three independent experiments

that HGF acts via the Akt-PI3-K axis to induce phosphorylation and suppress activation of rac1.

\section{Discussion}

Although the antiapoptotic effects of HGF are well known, our findings are the first to show that HGF suppresses apoptosis by inhibiting rac1-regulated oxidative stress. Moreover, our data show that activation of the PI3-K-Akt prosurvival pathway is essential and sufficient for HGF's effects on rac1, and rac1-regulated ROS production.

Interestingly, HGF itself does not induce any changes in the intracellular redox state. This is somewhat surprising since many other receptor tyrosine kinase-linked growth factors such as PDGF and EGF, and cytokines such as TNF- $\alpha$ and IL$1 \beta$ employ ROS as signaling intermediaries. ${ }^{36-38}$ For a growth factor, HGF seems to function in a unique fashion in that it does not employ ROS as its own downstream signaling molecules, but rather inhibits one of the cellular machineries responsible for ROS generation. In this regard, the serine phosphorylation of rac1 by HGF provides a novel molecular mechanism for suppression of intracellular oxidative stress.

Rac1 is of growing importance in $H / R$ and $I / R$ settings. Somewhat paradoxically, activation of rac1 in such prooxidative settings is closely coupled to activation of Akt. How then could activation of the PI3-K-Akt axis result in downregulating rac1 activity, and suppressing oxidative stress? The answer to this paradox lies in understanding that activation of $\mathrm{PI} 3-\mathrm{K}$ and Akt is a compensatory prosurvival 
mechanism in response to oxidative stimuli. Preactivation of this mechanism, as with HGF or expression of activated alleles of Akt or PI3-K, before the oxidative stimulus, inhibits oxidative stress and offers protection from death induced by that stimulus. This compensatory mechanism, if activated after the oxidative stimulus and oxidative stress, may act to suppress subsequent ROS production (by inhibiting rac1 function), but at that particular time is not sufficient to prevent cell death. This is borne out by our observations that (1) Akt was activated even in the setting of cell death induced by $\mathrm{H} / \mathrm{R}$ (data not shown) and (2) HGF offered no protection against cell death if administered after the hypoxic stimulus.

It is also likely that, in contrast to the proapoptotic $H / R$ stimulus, under more controlled conditions of ROS production such growth factors (angiotensin II, PDGF, EGF, etc.), rac1 and Akt have a more symbiotic relationship. ${ }^{1,36,37,39,40}$. In such scenarios, rac1 and rac1-regulated ROS, through activation of Akt, may promote growth and prevent cell death. In fact, such prosurvival effects of rac1-regulated ROS have been demonstrated. ${ }^{12,38,41}$

In summary, our findings implicate a novel relationship between the PI3-K-Akt axis and rac1 in the control of intracellular redox state. The balance of this relationship, controlled by prosurvival and prodeath stimuli such as HGF and $H / R$, respectively, and the timing between such stimuli, has a profound impact on the fate of the cell. Rac1, PI-3K, and Akt are expressed and operative in all cell types, implying that the relationship described herein may be relevant in a broad variety of cell types and tissues.

\section{Materials and Methods}

\section{Preparation of rat hepatocytes and H/R experiment}

Rat hepatocytes were prepared freshly from Lewis rat (male, 250-300 g) by conventional collagenase method. The isolated hepatocytes were seeded in plastic dishes coated with rat-tail collagen $\left(3 \times 10^{6}\right.$ cells per $100 \mathrm{~mm}$ dish) and cultured with William's E complete medium (Gibco, NY, USA) supplemented with $10 \%$ fetal bovine serum, $10^{-9} \mathrm{~mol} / \mathrm{l}$ insulin, and $10^{-9} \mathrm{~mol} / /$ dexamethasone in a humidified atmosphere of $5 \% \mathrm{CO}_{2} / 95 \%$ air at $37^{\circ} \mathrm{C}$. Medium was replaced by William's $\mathrm{E}$ medium without serum, insulin, and dexamethasone $16 \mathrm{~h}$ before the experiment. Hypoxic condition was attained in a modulator incubator chamber (BillupsRothenberg, CA, USA) by flushing the chamber with a $95 \% \mathrm{~N}_{2} / 5 \% \mathrm{CO}_{2}$ gas mixture for $10 \mathrm{~min}$ and sealing the chamber. This method has been shown to achieve a $\mathrm{pO}_{2}$ of $10 \pm 5$ Torr. Following $4 \mathrm{~h}$ of hypoxia, reoxygenation of hepatocytes was obtained by opening the chamber and by replacing the hypoxic medium with oxygenated medium.

\section{Adenoviral vectors and recombinant human HGF (rhHGF)}

HA-epitope-tagged dominant negative mutant of Akt in which Thr308 and Ser473 are replaced by alanine (AxCAAkt-AA), a dominant negative mutant of the p85 subunit of PI3-K (AxCAdelta-p85), constitutively activated mutant of Akt (myristoylated Akt: Myr-Akt), and constitutively activated mutant of PI3-K (myristoylated p110: Myr-p110) were kindly provided by Dr. W Ogawa and Dr. M Kasuga (Kobe, Japan). An adenoviral vector encoding Escherichia coli lacZ gene (AdLacZ) was used as a control vector. Adenoviral vector was infected to hepatocytes at $5 \mathrm{moi} 48 \mathrm{~h}$ prior to the experiment, and rhHGF provided by Mitsubishi Chemical Corporation (Yokohama, Japan) was administered to hepatocytes $2 \mathrm{~h}$ prior to hypoxic insult at the concentration of $40 \mathrm{ng} / \mathrm{ml}$, unless indicated. rhHGF obtained was blotted with anti- $\alpha$-chain of HGF $(2 \mu \mathrm{g} / \mathrm{ml}$, Santa Cruz Biotechnology Inc., CA, USA) to confirm the activated form. Catalase, wortmannin, and Ly294002 were purchased from Roche (Basel, Switzerland), and $\mathrm{N}$-acetyl cysteine (NAC) from Sigma (MO, USA).

\section{Analyses for apoptosis, oxidative damage, and Akt activities of hepatocytes}

For evaluation of apoptosis, an enzyme-linked immunosorbent assay (ELISA) kit (Cell Death Detection ELISA ${ }^{\text {PLUS; }}$; Roche, Basel, Switzerland) was used according to the manufacturer's instructions. The principle of this test is based on the detection of mono- and oligonucleosomes in the cytoplasmic fractions of cell lysates by using biotinylated antihistone- and peroxidase-coupled anti-DNA antibodies. Hepatocellular necrosis induced by $H / R$ was estimated by measuring $L D H$ levels of the culture medium. DNA-damage biomarker Kit '8-OHdG Check plus', purchased from Japan Institute for the Control of Aging (Shizuoka, Japan), was used for the evaluation of oxidative stress in hepatocytes. Aliquots of the culture media were used for the oxidative stress assay. 8-OHdG Check is a competitive in vitro ELISA for quantitative measurement of the oxidative DNA adducts, 8-OHdG, in DNA with very high sensitivity.

Akt activity assay was performed using the Akt kinase Assay Kit (Cell Signaling, MA, USA) according to the manufacturer's instructions. Wholecell extracts from $3 \times 10^{6}$ hepatocytes were immunoprecipitated with immobilized $\alpha$-Akt, and in vitro kinase assay was performed using GSK-3 fusion protein as a substrate according to the manufacturer's instructions. Phosphorylation of GSK-3 was detected with antiphospho-GSK-3.

\section{Intracellular ROS measurement}

Cells $\left(1 \times 10^{4}\right)$ of hepatocytes were seeded in $35 \mathrm{~mm}$-glass bottom dish $24 \mathrm{~h}$ before the experiment when adenovirus was not to be infected. The adenoviruses were infected for $5 \mathrm{~h}$ in serum-free medium $48 \mathrm{~h}$ before $H / R$ experiment, when necessary. ROS production of the hepatocytes was observed with confocal laser scan microscopy (Olympus, Tokyo, Japan) after staining cells with 5,6-chloromethyl-2,7-dichlorodihydrofluorescein diacetate (CM- $\mathrm{H}_{2}$ DCF-DA, $250 \mu \mathrm{M}$ in HBSS) for $10 \mathrm{~min}$.

\section{rac1 activity and rac1 phosphorylation assays}

rac1 activity was measured using the 'rac1 activation kit' (Upstate Biotechnology, NY, USA) with slight modification. Briefly, whole-protein extracts were immunoprecipitated with protein binding domain of p21 activation kinase-1 (PAK1-PBD). PAK1-PBD only binds to activated forms of rac1 and cdc42. Immunoprecipitated proteins were separated in SDSPAGE (10\%) and blotted with anti-rac1 $(1 \mu \mathrm{g} / \mathrm{ml}$, Santa Cruz Biotechnology Inc., CA, USA). For rac1 phosphorylation assay, whole cell extracts were immunoprecipitated with anti-rac1 (Santa Cruz Biotechnology Inc., CA, USA), separated in SDS-PAGE (10\%) and blotted with antiphospho serine (Chemicon, CA, USA).

\section{Statistical analysis}

All results were expressed as mean \pm S.E.M. of at least three independent experiments. A one-way ANOVA was used for multiple comparisons. A value of $P<0.05$ was considered significant. 


\section{Acknowledgements}

We thank $W$ Ogawa and $M$ Kasuga for providing adenoviral vectors (AxCAAkt-AA, AxCAdelta-p85, Myr-Akt, and Myr-p110), and T Ishii for recombinant human HGF. We also thank Miss $Y$ Nagata for excellent technical support in confocal laser scan microscopy.

\section{References}

1. Sundaresan M, Yu ZX, Ferrans VJ, Sulciner DJ, Gutkind JS, Irani K, Goldschmidt Clermont PJ and Finkel T (1996) Regulation of reactive-oxygenspecies generation in fibroblasts by Rac1. Biochem. J. 318(Part 2): 379-382.

2. Ozaki M, Deshpande SS, Angkeow P, Suzuki S and Irani K (2000) Rac1 regulates stress-induced, redox-dependent heat shock factor activation. J. Biol. Chem. 275: 35377-35383.

3. Ozaki M, Kawabata T and Awai M. (1988) Iron release from haemosiderin and production of iron-catalysed hydroxyl radicals in vitro. Biochem. J. 250: 589595

4. Suzuki Y, Ono Y and Hirabayashi Y (1998) Rapid and specific reactive oxygen species generation via NADPH oxidase activation during Fas-mediated apoptosis. FEBS Lett. 425: 209-212

5. Abdi S and Ali A (1999) Role of ROS modified human DNA in the pathogenesis and etiology of cancer. Cancer Lett. 142: 1-9

6. Arakaki N, Kajihara T, Arakaki R, Ohnishi T, Kazi JA, Nakashima H and Daikuhara $Y$ (1999) Involvement of oxidative stress in tumor cytotoxic activity of hepatocyte growth factor/scatter factor. J. Biol. Chem. 274: 13541-13546

7. Ozaki M, Deshpande SS, Angkeow P, Bellan J, Lowenstein CJ, Dinauer MC, Goldschmidt Clermont PJ and Irani K (2000) Inhibition of the Rac1 GTPase protects against nonlethal ischemia/reperfusion-induced necrosis and apoptosis in vivo. FASEB J. 14: 418-429

8. Kim KS, Takeda K, Sethi R, Pracyk JB, Tanaka K, Zhou YF, Yu ZX, Ferrans VJ, Bruder JT, Kovesdi I, Irani K, Goldschmidt Clermont P and Finkel T (1998) Protection from reoxygenation injury by inhibition of rac1. J. Clin. Invest. 101: 1821-1826

9. Heyworth PG, Knaus UG, Settleman J, Curnutte JT and Bokoch GM (1993) Regulation of NADPH oxidase activity by Rac GTPase activating protein(s). Mol. Biol. Cell 4: 1217-1223

10. Gorzalczany Y, Sigal N, Itan M, Lotan O and Pick E (2000) Targeting of Rac1 to the phagocyte membrane is sufficient for the induction of NADPH oxidase assembly. J. Biol. Chem 275: 40073-40081

11. Faris SL, Rinckel LA, Huang J, Hong YR and Kleinberg ME (1998) Phagocyte NADPH oxidase p67-phox possesses a novel carboxylterminal binding site for the GTPases Rac2 and Cdc42. Biochem. Biophys. Res. Commun. 247: 271276

12. Irani K, Xia Y, Zweier JL, Sollott SJ, Der CJ, Fearon ER, Sundaresan M, Finkel T and Goldschmidt Clermont PJ (1997) Mitogenic signaling mediated by oxidants in Ras-transformed fibroblasts. Science 275: 1649-1652

13. Yeh LH, Park YJ, Hansalia RJ, Ahmed IS, Deshpande SS, Goldschmidt Clermont PJ, Irani K and Alevriadou BR (1999) Shear-induced tyrosine phosphorylation in endothelial cells requires Rac1-dependent production of ROS. Am. J. Physiol. 276: C838-C847

14. Wang Z, Castresana MR and Newman WH (2001) Reactive oxygen and NFkappaB in VEGF-induced migration of human vascular smooth muscle cells. Biochem. Biophys. Res. Commun. 285: 669-674

15. Rattan V, Sultana C, Shen Y and Kalra VK (1997) Oxidant stress-induced transendothelial migration of monocytes is linked to phosphorylation of PECAM-1. Am. J. Physiol. 273: E453-E461

16. Doanes AM, Irani K, Goldschmidt Clermont PJ and Finkel T (1998) A requirement for rac1 in the PDGF-stimulated migration of fibroblasts and vascular smooth cells. Biochem. Mol. Biol. Int. 45: 279-287

17. Moore KA, Sethi R, Doanes AM, Johnson TM, Pracyk JB, Kirby M, Irani K, Goldschmidt Clermont PJ and Finkel T (1997) Rac1 is required for cell proliferation and G2/M progression. Biochem. J. 326(Part 1): 17-20

18. Nakamura T, Nawa K and Ichihara A (1984) Partial purification and characterization of hepatocyte growth factor from serum of hepatectomized rats. Biochem. Biophys. Res. Commun. 122: 1450-1459
19. Nakamura T, Nawa K, Ichihara A, Kaise N and Nishino T (1987) Purification and subunit structure of hepatocyte growth factor from rat platelets. FEBS Lett. 224: 311-316

20. Matsumoto K and Nakamura T (1997) Hepatocyte growth factor (HGF) as a tissue organizer for organogenesis and regeneration. Biochem. Biophys. Res. Commun. 239: 639-644

21. Ohmichi $\mathrm{H}$, Matsumoto $\mathrm{K}$ and Nakamura $\mathrm{T}$ (1996) In vivo mitogenic action of HGF on lung epithelial cells: pulmotrophic role in lung regeneration. Am. J. Physiol. 270: L1031-L1039

22. Michalopoulos GK (1995) HGF in liver regeneration and tumor promotion. Prog. Clin. Biol. Res. 391: 179-185

23. Brinkmann V, Foroutan H, Sachs M, Weidner KM and Birchmeier W (1995) Hepatocyte growth factor/scatter factor induces a variety of tissue-specific morphogenic programs in epithelial cells. J. Cell Biol. 131: 1573-1586

24. Van Belle E, Witzenbichler B, Chen D, Silver M, Chang L, Schwall R and Isner JM (1998) Potentiated angiogenic effect of scatter factor/hepatocyte growth factor via induction of vascular endothelial growth factor: the case for paracrine amplification of angiogenesis. Circulation 97: 381-390

25. Bussolino F, Di Renzo MF, Ziche M, Bocchietto E, Olivero M, Naldini L, Gaudino G, Tamagnone L, Coffer A and Comoglio PM (1992) Hepatocyte growth factor is a potent angiogenic factor which stimulates endothelial cell motility and growth. J. Cell Biol. 119: 629-641

26. Takayama $H$, LaRochelle WJ, Sharp R, Otsuka T, Kriebel $P$, Anver M, Aaronson SA and Merlino G (1997) Diverse tumorigenesis associated with aberrant development in mice overexpressing hepatocyte growth factor/scatter factor. Proc. Natl. Acad. Sci. USA 94: 701-706

27. van der Voort R, Taher TE, Derksen PW, Spaargaren M, van der Neut R and Pals ST (2000) The hepatocyte growth factor/Met pathway in development, tumorigenesis, and B-cell differentiation. Adv. Cancer Res. 79: 39-90

28. Dong G, Chen Z, Li ZY, Yeh NT, Bancroft CC and Van Waes C (2001) Hepatocyte growth factor/scatter factor-induced activation of MEK and PI3K signal pathways contributes to expression of proangiogenic cytokines interleukin-8 and vascular endothelial growth factor in head and neck squamous cell carcinoma. Cancer Res. 61: 5911-5918

29. Fan S, Ma YX, Gao M, Yuan RQ, Meng Q, Goldberg ID and Rosen EM (2001) The multisubstrate adapter Gab1 regulates hepatocyte growth factor (scatter factor)-c-Met signaling for cell survival and DNA repair. Mol. Cell Biol. 21: 4968-4984

30. Delehedde M, Sergeant N, Lyon M, Rudland PS and Fernig DG (2001) Hepatocyte growth factor/scatter factor stimulates migration of rat mammary fibroblasts through both mitogen-activated protein kinase and phosphatidylinositol 3-kinase/Akt pathways. Eur. J. Biochem. 268: 4423-4429

31. Nakagami H, Morishita R, Yamamoto K, Taniyama $Y$, Aoki M, Matsumoto K, Nakamura T, Kaneda Y, Horiuchi M and Ogihara T (2001) Mitogenic and antiapoptotic actions of hepatocyte growth factor through ERK, STAT3, and AKT in endothelial cells. Hypertension 37: 581-586

32. Xiao GH, Jeffers M, Bellacosa A, Mitsuuchi $Y$, Vande Woude GF and Testa JR (2001) Anti-apoptotic signaling by hepatocyte growth factor/Met via the phosphatidylinositol 3-kinase/Akt and mitogen-activated protein kinase pathways. Proc. Natl. Acad. Sci. USA 98: 247-252

33. Kosai K, Matsumoto K, Nagata S, Tsujimoto $Y$ and Nakamura T (1998) Abrogation of Fas-induced fulminant hepatic failure in mice by hepatocyte growth factor. Biochem. Biophys. Res. Commun. 244: 683-690

34. Kosai K, Matsumoto K, Funakoshi H and Nakamura T (1999) Hepatocyte growth factor prevents endotoxin-induced lethal hepatic failure in mice. Hepatology 30: 151-159

35. Kwon T, Kwon DY, Chun J, Kim JH and Kang SS (2000) Akt protein kinase inhibits Rac1-GTP binding through phosphorylation at serine 71 of Rac1. J. Biol. Chem. 275: 423-428

36. Sundaresan M, Yu ZX, Ferrans VJ, Irani K and Finkel T (1995) Requirement for generation of $\mathrm{H}_{2} \mathrm{O} 2$ for platelet-derived growth factor signal transduction. Science 270: 296-299

37. Bae YS, Kang SW, Seo MS, Baines IC, Tekle E, Chock PB and Rhee SG. (1997) Epidermal growth factor (EGF)-induced generation of hydrogen peroxide. Role in EGF receptor-mediated tyrosine phosphorylation. J. Biol. Chem. 272: 217-221

38. Deshpande SS, Angkeow P, Huang J, Ozaki M and Irani K (2000) Rac1 inhibits TNF-alpha-induced endothelial cell apoptosis: dual regulation by reactive oxygen species. FASEB J. 14: 1705-1714 
39. Thannickal VJ, Day RM, Klinz SG, Bastien MC, Larios JM and Fanburg BL (2000) Ras-dependent and -independent regulation of reactive oxygen species by mitogenic growth factors and TGF-beta1. FASEB J. 14: 1741-1748

40. Mills EM, Takeda K, Yu ZX, Ferrans V, Katagiri Y, Jiang H, Lavigne MC, Leto TL and Guroff $G$ (1998) Nerve growth factor treatment prevents the increase in superoxide produced by epidermal growth factor in PC12 cells. J. Biol. Chem. 273: 22165-22168

41. Pani G, Colavitti R, Bedogni B, Anzevino R, Borrello S and Galeotti T (2000) A redox signaling mechanism for density-dependent inhibition of cell growth. $\mathrm{J}$. Biol. Chem. 275: 38891-38899 